\title{
An Evidence-Based Management Approach to HIV/AIDS in Nigeria
}

\author{
Tegan Mosugu \\ Graduate School of Public \& International Affairs, University of Pittsburgh, Pittsburg, USA \\ Email: teganjmosugu@gmail.com
}

How to cite this paper: Mosugu, T. (2021) An Evidence-Based Management Approach to HIV/AIDS in Nigeria. World Journal of AIDS, 11, 120-142.

https://doi.org/10.4236/wja.2021.113010

Received: May 10, 2021

Accepted: September 25, 2021

Published: September 28, 2021

Copyright $\odot 2021$ by author(s) and Scientific Research Publishing Inc. This work is licensed under the Creative Commons Attribution International License (CC BY 4.0).

http://creativecommons.org/licenses/by/4.0/

\begin{abstract}
Objectives: This paper seeks to examine the history of HIV/AIDS in Nigeria while presenting a clear picture of some of the issues that exist in service delivery. Lastly, this paper explores how an evidence-based management approach offers an effective set of tools to HIV/AIDS organizations. Methods: Content analysis and a qualitative desk review of the literature. Results: Findings from this paper reveal that through the use of evidence-based management, preconceived notions can be challenged so as to yield a diversity of thought and a more people-centered approach to public health delivery. This paper also shows that in the Nigerian setting, an evidence-based management framework can be a transformative tool in ensuring that key populations can receive critical care and treatment in the long run despite the uncertainty that might exist when it comes to funding and resources. Conclusions: Evidence-based management is a rigorous framework that can be used for understanding how a multitude of factors can position an organization to achieve its theory of change, which in turn can lead to sustainable impact in the long run. Incorporating the use of evidence in everyday organizational behavior involves not only looking at the manner in which data is aggregated, but also how it is disseminated. In order to ensure that the evidence is not manipulated, nonprofit organizations are often viewed as being best suited for collecting evidence since they are not heavily plagued by systemic corruption and political tides, compared to their government counterparts.
\end{abstract}

\section{Keywords}

Evidence-Based Management, HIV/AIDS, Nigeria, Healthcare, Service

Delivery Treatment of HIV/AIDS Prevention of HIV/AIDS Epidemiology of HIV/AIDS

\section{Introduction}

Globally, 37.9 million people are living with HIV, and 21\% of people do not know 
that they have the virus. Africa is home to $69 \%$ of new HIV infections, as well as the $91 \%$ of HIV positive children [1]. Nigeria, the most populous country in Africa has the second largest epidemic in the world [1]. The United Nations estimates that Nigeria is set to have the third highest population in the world. Therefore, efforts must be put in place to alleviate the HIV/AIDS epidemic for vulnerable groups of people.

In Nigeria, the National HIV and AIDS Strategic Framework seeks to diagnose $90 \%$ of all HIV/AIDS positive individuals so that they can receive the necessary treatment [2]. Achieving this involves assessing various aspects of service delivery such as supply chain management, funding, advocacy, organizational processes, organizational leadership, preventive and treatment services. The sum of these individual factors constitutes evidence-based management (EBMgt), which can be used to shape an organization's outcomes. When incorporated within and across nongovernmental organizations, this approach can inform decision-making by aggregating and appraising key information, facts, or data and juxtaposing it from various sources: literature, practitioners, stakeholders, and organizations. In the Nigerian context, EBMgt can be used to challenge preconceived, which in turn promotes a diversity of thought in value-based and mission-centered organizations catering to the needs of key populations.

As of 2019, it was estimated that 1.8 million Nigerians were living with HIV. With an adult HIV/AIDS prevalence rate (15 - 49) of 1.4\%, Nigeria still has a long way to go in its fight against AIDS. Nigeria's HIV adult prevalence rate has reduced from approximately $6 \%$ in 2001 to $1.4 \%$ at the end of 2020 . Furthermore, $68 \%$ of adults with HIV are on antiretroviral treatment (aRT), while only $36 \%$ of children are on aRT [1]. Six states primarily account for $41 \%$ of the persons living with HIV/AIDS (PLWHA). They are: Kaduna, Akwa Ibom, Benue, Lagos, Oyo, and Kano (see Figure 1 and Figure 2).

The low prevalence rate of HIV does not mean that Nigeria is better than most countries when it comes to tackling the HIV burden. As a matter of fact, Nigeria has the highest rate of new infections based on the number of people that are aware of their status; and it also has the second-largest HIV epidemic in the world [1]. It is estimated that $50 \%$ of Nigerians with HIV do not know their status, and among the adult population that is aware of their positive diagnosis, only $89 \%$ of them are accessing antiretroviral treatment [1]. Moreover, there is also no concrete data on the percent of those whose HIV conditions are virally suppressed.

In comparison to the rest of the population, certain groups tend to have a higher HIV burden. These groups include: commercial sex workers (CSWs), sexual minorities, and people who inject drugs (PWID). In addition, women (Figure 3 ) and children tend to be disproportionately affected by the HIV virus as compared to their heterosexual male counterparts. In 2016, public health statistics revealed that $14.4 \%$ of sex workers were living with the virus. Despite the high prevalence rate in this group, data collected by NACA [2] and UNAIDS [3] shows that $98.1 \%$ of commercial sex workers reported using condoms with their 


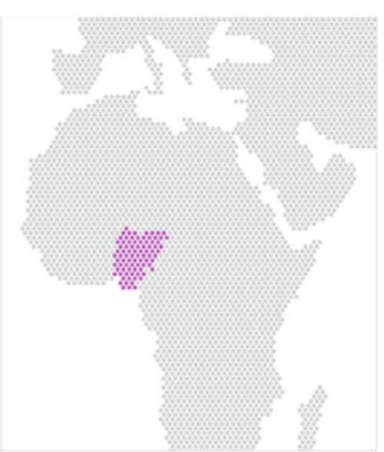

Nigeria (2018)

1.9 m people living with HIV

$1.5 \%$ adult HIV prevalence (ages 15 - 49)

130,000 new HIV infections

53,000 AIDS-related deaths

$55 \%$ adults on antiretroviral treatment

$35 \%$ children on antiretroviral treatment

*All adults/children living with HIV

Source: UNAIDS Data 2019

Figure 1. HIV/AIDS-Nigeria profile.

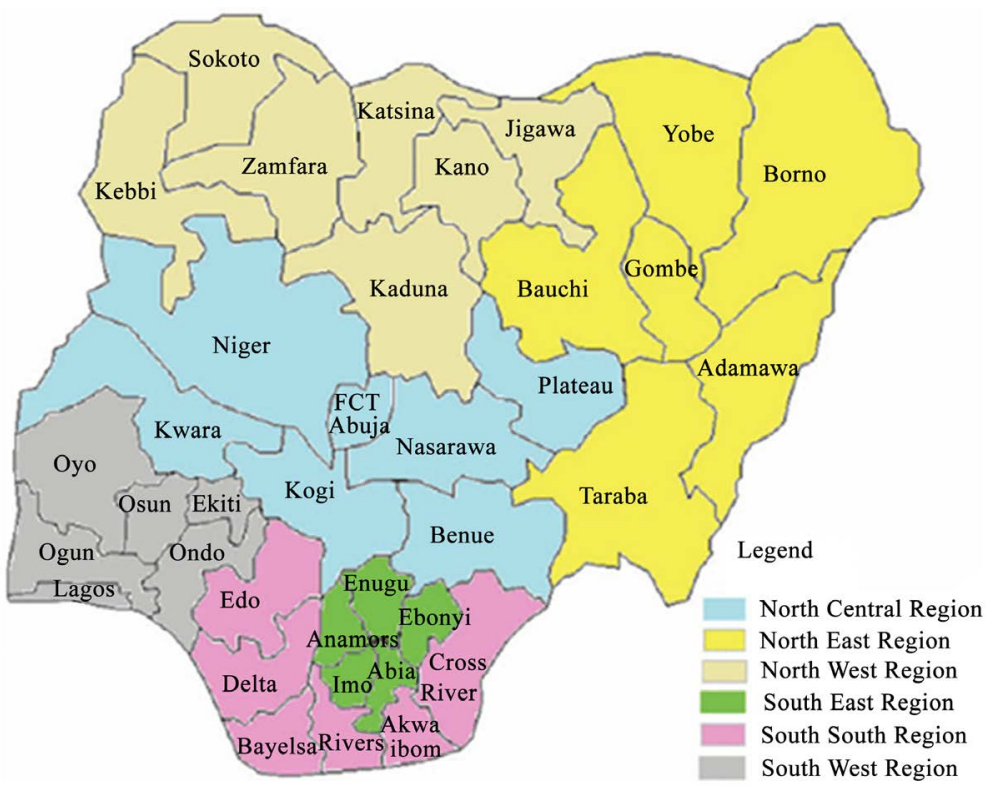

Figure 2. Map of Nigeria. Source: (Gayawan et al., 2014).

\section{NIGERIA New HIV infections by age and sex (2017)}

Children and adults
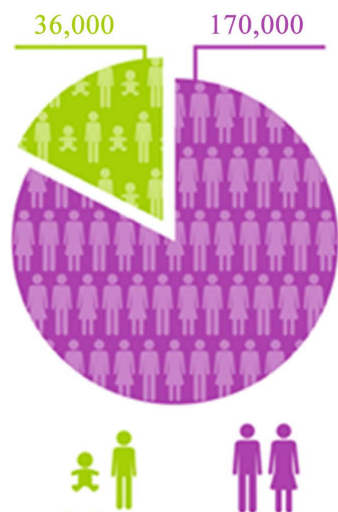

Children

$(0-14)$

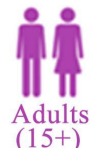

Adolescents
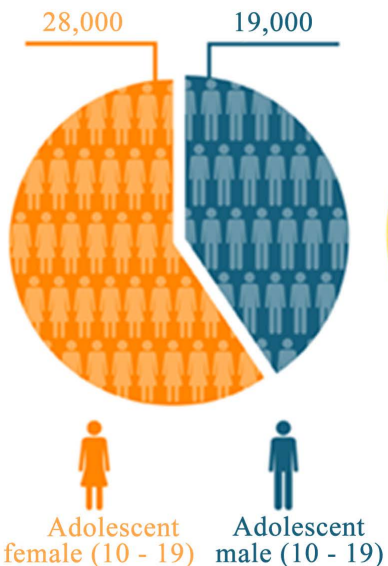

female $(10-19)$ male $(10-19)$

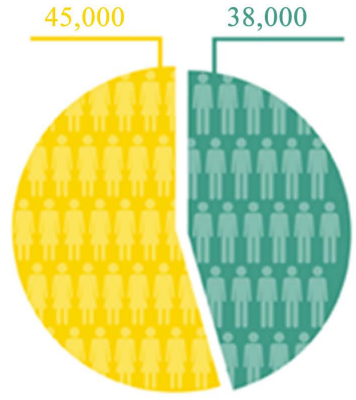

Young people

Source: UNAIDS Data 2018

Avert) www.avert.org

Figure 3. HIV Infections by age and sex. 
last sexual partner and $97.1 \%$ of them received a HIV test in the last 12 months [2] [3]. In a public health behavior study, some of these individuals reported using a condom with their last partner; however, it is unclear if such accounts are true and what the percentage of CSWs living with HIV are seeking treatment [4]. One of the major reasons why female sex workers are less likely to seek treatment stems from sex work being illegal in Nigeria [4]. They are apprehensive of what the legal consequences of their actions could be. In some cases, being caught by law enforcers can lead to them appeasing the police either through money or sex, and those that refuse to do so can be raped and be more susceptible to HIV.

PWID are also susceptible to HIV since they share needles and syringes. This increases their chances of contracting the virus since drug use has been shown to impair judgment and lead to sexual risk behaviors. The average age of drug use in the country is 15 years which means that people younger than 15 years are equally at risk of contracting the virus. The risk of contracting other STIs also varies for PWID who consummately use drugs, with amphetamine users being the most at-risk [5].

Sexual minorities such as women who have sex with women (WSW) and men who have sex with men (MSM) also have a high risk of contracting HIV. In Nigeria, laws such as the Same Sex Marriage Prohibition Act criminalize the behaviors of LGBTQ+ members of the society and make it hard for them to seek care which reduces their access to Pre-exposure prophylaxis (PrEP) and antiretroviral drugs. The mere act of requesting access to care does not mean that such services are guaranteed since the decision still falls at the discretion of the healthcare worker. A public opinion poll of Nigerian healthcare professionals revealed that only $30 \%$ of healthcare professionals believe that these sexual minorities should have access to health care [6]. Thus, stigma not only poses a barrier to prevention, but also stifles access to essential treatment and care for key (vulnerable) populations.

These vulnerable groups account for more than $32 \%$ of new infections in $\mathrm{Ni}$ geria [2]. They are integrated into different parts of the social fabric and it is important that policies and services that are aimed at tackling the spread of the disease are inclusive of them in the design and implementation stage. Such an approach would enable specific interventions to be created that can cater to their respective needs.

\subsection{History of HIV/AIDS in Nigeria}

The first case of HIV/AIDS in Nigeria was recorded in 1985 [7]. Two cases of a 13-year-old sexually active girl and a female commercial sex worker were recorded in Nigeria, in the Southern states of Lagos and Enugu [7]. During the late 20th century, Nigeria's HIV/AIDS prevalence rate had steadily increased. In 1991$1992,1993-1994,1995-1996$, the nation recorded a prevalence rate of $6.2 \%, 8.2 \%$, and $11 \%$ respectively ([7], p. 168). Throughout the past three decades, some statistics did not change. For example, HIV was more prevalent in individuals be- 
tween the ages of $25-29$, and the majority of infections were women. Other factors that were responsible for the spread of the disease included: "high prevalence/presence of untreated STDs among many Nigerians, high prevalence of tuberculosis, and lack of male circumcision among some Nigerian groups." ([7], p. 169). In some rural communities, there was also the belief that sleeping with virgins was a solution for the virus, and this led to an increased prevalence rate among women.

Health research has shown that throughout the years there is a high percentage of people in Nigeria with good and accurate knowledge of the epidemic [8] [9] [10]. However, an awareness of effective behavior and practices does not translate to positive healthy behaviors or even behavior change [11]. Although knowledge has been identified as a positive tool for positive change in all aspects of human endeavor, there are knowledge gaps when it comes to people's abilities to implement such knowledge. For example, in the 1980s and 1990s, people traditionally had several misconceptions about both the virus and disease. These misconceptions were held primarily by those with little education. Nevertheless, there was also a significant proportion of the population who were educated that believed that AIDS was a "retribution from God for promiscuity and believed that casual contacts could transmit the virus from an infected person to a healthy one" [12].

Throughout the subsequent decades, knowledge about HIV/AIDS and sexual practices has increased. However, outcomes have not necessarily improved. Ogbuji [10] highlights that $90 \%$ of university students in Ibadan, Nigeria had good knowledge about the disease and its transmission. In a survey of 217 students, only fifty-nine of them attested to being sexually active and among that group, and only nine had admitted to using a condom three months before the study. This suggests that although there was knowledge on how the virus could be contracted, personal preferences took precedence over scientific evidence. People were less likely to use condoms since they "hinder their sexual satisfaction, cause health problems and reduce their sexual interest" [10]. As a result, the attitudes of health professionals during the HIV/AIDS service delivery process are important.

Ohnishi et al. [13] explore the attitudes that caregivers and non-givers in the community have surrounding AIDS and how that impacts service delivery. They present a plethora of factors that lead to positive attitudes towards care of orphans living with HIV/AIDS. These factors include age, koranic schooling, polygamy, belief that there are increasing orphans in the community, and having relatives or friends with HIV/AIDS. The researchers deduced that people who had lower educational status did not have optimal knowledge of HIV/AIDS. On the other hand, younger people, especially younger women tend to have more positive attitudes toward vulnerable populations affected by the virus. Ohnishi et al. [13] point out that caregivers must be aware that there is no association between their religious affiliation and changes in preventive behavior. Therefore, it is critical that interventions designed to combat the HIV/AIDS epidemic are 
structural interventions since the presence of knowledge does not lead to behavior modifications on the individual level.

Balogun [7] examines the spread of HIV/AIDS in Nigeria by classifying the national response to HIV/AIDS under two eras: 1986-2001 and 2001-2007. In 1986, the Ministry of Health's response to HIV/AIDS included the establishment of an 18-Member National Experts Advisory Committee on AIDS (NECA) whose goals were set to assess the situation on the ground. NECA was later replaced by the National AIDS Control Programme (NACP) in 1988. In 1992, the government launched a national war against AIDS and recognized the intersection between HIV/AIDS and other sexually transmitted infections. This led to a merger that forged the National AIDS and STI Control Programme (NASCP) with each state having its own state AIDS and STI Control Programme (SASCP). ([14], p. 171).

NASCP was the precursor for the National Action Committee on AIDS (NACA). In 2007, NACA emerged following an endorsement from the National Council on Health on the need for a multi-sectoral approach to address the national struggle against HIV/AIDS. As a result, "the mandate for NACA is to spearhead "the overall coordination and direction of HIV/AIDS expanded responses of all sectors and at all levels in Nigeria including collaboration with international bodies" ([14], p. 171). As part of its approach, NACA works with civil society, faith-based coalitions, business coalitions, and youth networks to combat the HIV epidemic in Nigeria. It is also decentralized and includes operations at the state level, i.e., state action committees, and local action committees on AIDS (LACAs) in its effort to combat HIV/AIDS.

Balogun [7] posits that a deep dive into some of the adaptive challenges hindering progress on HIV goals in Nigeria reveals issues surrounding AIDS stigma, discrimination, and exclusion. In 2005, NACA joined forces with the Federal Ministry of Labour, and Productivity to create a National Workplace Policy on HIV/AIDS. This was modeled after the International Labour Organization that stressed the need for places of work to promote human rights, social justice, and equity in their operational practices. Nonetheless, the federal government did not have a strategic plan that it planned on utilizing in its efforts to protect human rights, instill justice and protection for people living with HIV/AIDS.

\subsection{The National HIV and AIDS Strategic Framework (2017-2021)}

The National HIV and AIDS Strategic Framework was set up to ensure the health and well-being of PLWHA, and to also address the high HIV burden in the country by instituting a sustained and effective national response to prevent new HIV infections. The plan seceded the 2010-2015 National Strategic Framework, which "provided a structure and plan for advancing the multi-sectoral response to the epidemic in Nigeria" ([2], para. 1). The current framework is crucial is because it is designed to incorporate a 90-90-90 strategy: diagnose $90 \%$ of all HIV/AIDS cases; provide $90 \%$ of all HIV-positive individuals with sustainable antiretroviral therapy, and achieve viral suppression for $90 \%$ of people living with the virus. 
Its framework is divided into five thematic areas: 1) Prevention of HIV among general and key populations, 2) HIV testing services (HTS), 3) Elimination of mother-to-child transmission of HIV (eMTCT), 4) HIV treatment, and 5) care [2]. The strategic framework also focuses on the importance of strengthening quality management when it comes to delivering services and achieving HIV targets and antiretroviral drug therapy commodities [2]. It suggests the need for an advocacy strategy by which HIV management happens through public and private actors as well as local, state, and national actors. Despite the existence of this policy, there is not any framework for effectively leading HIV programs/ services through the change process as they reach their respective communities.

\section{HIV/AIDS Service Delivery in Nigeria}

\section{HIV/AIDS in the National Health System}

Although there are national and international efforts to combat HIV/AIDS in Nigeria, only thirty-three percent of people living with the virus have access to essential medication and treatment. Thus, there is a large number of people that are in need of HIV/AIDS services. Social stigma, discrimination, and punitive laws for marginalized groups also exacerbate the likelihood of not getting tested and seeking treatment. In order for the country to diminish its rate of infection, evidence regarding the nature of service delivery must be gathered and appraised so as to inform stakeholders and strengthen the decision-making process.

The decision-making process can often lead to service delivery challenges especially when resources-or the distribution and management of it-are not optimal. Service delivery issues can arise as a byproduct of poor technical management of HIV/AIDS services, lack of country ownership, ineffective supply chain management systems, and the lack of a sustainability plan. More often than not, there is a disconnect that exists when it comes to integrating HIV/ AIDS services into the fabric of the Nigerian health system. This is because of the lack of coordination that exists among the multiple actors who more often than not work in silos. Itiola and Agu [15] reveal that "the emergency response phase to HIV epidemic in Nigeria and other countries saw to the deployment of donors' resources with little consideration for country ownership (CO) and sustainability" ([15], p. 1). Despite the availability of these emergency response resources, the initial stage of building a national response to the HIV/AIDS response involved international organizations building programs away from hospitals [16]. Subsequently, the response intensified due to the rate by which people were getting the virus. However, as the prevalence rate of the virus reduced, a lesser proactive response became the order of the day.

Presently, the HIV epidemic is treated as a "lesser disease" that only affects a select few; thus, the epidemic is not getting as much attention as it should. A research study regarding the role media coverage plays in HIV/AIDS in the multi-sectoral and community-based response to HIV/AIDS shows that there has been a dial down in recent years. This has been characterized by a shift from the 
cognitive (emphasis on decision-making) model to the activity (individual context) model of HIV/AIDS communication. In order to ensure that more positive outcomes are achieved, there ought to be more of a focus on the disease.

Evidence from literature suggests that a shift in paradigm is needed for Nigeria to attain sustainable HIV programs and services. Oleribe et al. [16] coin the term "communization" that makes the disease relatable to other health ailments. The process of commonization integrates the epidemic into the fray of other health disparities whereby it is "seen as a health condition like others. It involves making HIV services available at all levels of healthcare" [16]. The process of commonization is a decentralized one that involves "integrating HIV care into the existing fabric of the healthcare system" ([16], p. 4).

Declassifying HIV/AIDS as a special disease is the first step in designing an essential package of HIV/AIDS; however, this has to be in tandem with more country involvement.

"Early identification of HIV-positive people in need of care through testing, appropriate initial and continued counseling, assessment of HIV disease stage, treatment with Anti-Retroviral Therapy for those who need it, monitoring while on treatment for efficacy, adherence and side-effects, detection and management of other complications of HIV infection, provision of sexual and reproductive health services as well as careful record-keeping" ([16], p. 12).

The design of treatment, care, and services cannot be heavily reliant on foreign donors. Hence, creating a diverse mix of funding streams would reduce the dependence on non-state actors, which would foster a greater level of country ownership. Nevertheless, these treatments and services cannot simply exist in theory, but translate in practice.

Appropriate budgeting is an effective means of ensuring that HIV programs and services get the financial commitment that they require at the country level. Recently, Nigeria launched an initiative that requires all states of the federation to contribute $1 \%$ of their monthly allocations to the national response. In 2019, the Network of People Living with HIV/AIDS called on the "federal government to increase support for people living with the disease in order to place more people on treatment" ([17], p. 1). As a whole, Nigeria has witnessed an increase in foreign funding for HIV/AIDS services in light of domestic funding still catching up. In 2012, the President's Emergency Plan for AIDS Relief (PEPFAR) and Global Fund for HIV/AIDS accounted for $43 \%$ and 33\% of HIV spending respectively while domestic spending accounted for $23 \%$ ([15], p. 8).

The low levels of spending on the part of the Nigerian government have led to ineffective supply chain management. HIV/AIDS practitioners advocate for privatization of the supply chain to establish transparency and accountability. Owing to the fact that government funding only covers the procurement of drugs and does not cover other miscellaneous expenses such as port clearance fees and distribution. Therefore, public health programs ought to achieve sustainability which is defined as the continuity of a program after the termination of donor(s) support [15]. As a result of the health system being rudimentarily weak and the 
over-dependent on international development partners, it has become the norm for programs to be short-lived. This creates a systemic problem wherein the health system is rudimentarily weak. Therefore, Nigeria's ability to self-finance its health sector would require planning and increased government revenue.

Stronger financing mechanisms cannot solely strengthen health outcomes. This is because there are other barriers associated with delivering HIV/AIDS services that include ineffective inter-organizational management, legal ramifications that criminalize certain sexual minority groups, and low number of care facilities (1078) - as estimated by Avert in the year 2018 that provide HIV treatment. Furthermore, user fees associated with getting tested prevent financially vulnerable individuals from not only knowing their status but also from receiving treatment. Tyler \& Dickinson [18] identify some factors that hinder prevention of the disease in the African region [18] and they include: materials never purchased and false claims of treatment, procurement and distribution issues, health workers using non-sterile equipment, exploitation of the sale of ART drug, theft, government corruption. Other factors that perpetuate the corruptive practices include officials increasing budget and siphoning off significant volumes of drugs without public awareness, lack of monitoring and oversight, diversion of funds by ministries, and extortion of funds from health workers. Tyler \& Dickinson argue that even when resources are present, there is still the tendency to mismanage them.

\section{Systemic Corruption \& Organizational Politics}

Delivering effective HIV/AIDS services in the Nigerian NGO landscape is often plagued by issues centered around corruption and organizational politics [19]. These two conditions can result in the deprivation of essential drugs/treatments from those in dire need. Corruption is a social and institutional issue that affects the delivery of public goods in Nigeria. In organizations, it is characterized by people seeking to profit off the system by all possible means. In a global ranking survey of 180 countries, Transparency International ranked Nigeria as the $144^{\text {th }}$ most corrupt nation out of 180 countries [20]. Two ethnographic studies reveal that despite Nigerian NGOs "sitting at the nexus of significant processes of social and political change, they are caught up in the social reproduction of inequality, exemplifying how local elites navigate the flow of global aid dollars and the politics of patronage to perpetuate inequality" [21]. The grafting practices that are associated with service delivery make it hard to implement bureaucratic accountability. As a result, it becomes nearly impossible for funding stakeholders to verify whether money has been spent for its actual purpose or the reports being presented have been falsified. Many times, it becomes nearly impossible for funders to distinguish between competent organizations/practitioners and those simply pursuing their self-interests.

In Nigeria, practitioners who pursue their own agenda away from donor goals and interests hope to acquire large sums of money. A 2011 national overhaul of 
the NGO space by the Independent Corrupt Practices and Other Related Offences Commission (ICPC) revealed that seven HIV/AIDS non-governmental organizations were responsible for fifteen fraudulent grants, in total of $\$ 474,519,260$ from 2003-2009 [22]. These grants were disbursed to well-established government and civil society organizations with headquarters in the capital city. A deeper look revealed that illegal funds were transferred outside the country, and that there were also extra-budgetary and undocumented expenditures. Fraud is ubiquitous in the country that even an audit by the Global AIDS Fund revealed that fraud and collusion by the National Agency of the Control of Aids totaled $\$ 3.8$ million in 2016 [23]. Although the proliferation of AIDS-related NGOs in Nigeria has provided advocacy and employment opportunities for people, it has also led to the phenomenon of "feeding fat on AIDS" in which some practitioners have been able to acquire wealth beyond their job provisions.

Organizational politics are also part of the fabric of HIV/AIDS organizations. These actions which are often behind-the-scenes often lead to some employees being financially better off than their counterparts. Pursuing one's self-interests while being involved in HIV/AIDS can be traced back to the 1990s during the onset of the epidemic, when some service providers used their work as a path to riches. Puis Okadigbo, the Country Program Officer of United against AIDS (UAA) in the 1990s was deemed as "greedy and self-aggrandizing" due to how he flaunted his wealth from earmarked funds. Unfortunately, this led to his demise because he chose to be ostentatious "instead of sharing some of his money to cultivate social ties and build a network of followers" ([24], p. 13) It is common practice for people to provide financial benefits as a reward to those who comply with altered reporting and accountability procedures. Moreover, a staunch opponent of everyone in an organization being financially better-off through illicit practices could be committing "career suicide", if he or she explicitly opposes the actions of the majority. This is why clientelism has become pervasive in Nigeria. Clientelism defined as a political or social system whereby support is given to a patron in lieu of a special privilege or benefit-makes it hard for individuals to speak up against organizational malpractices since they are better off supporting organizational ills. Conversely, when employees decide to go against the status quo by speaking up, their ulterior motives are questioned since the notion of a "good patron is becoming suspect in Nigeria's changing political economy" ([24], p. 13) Consequently, people begin to question good practices and raise eyebrows as to what the interests or motives of others are and whether they are trying to reduce an organization's ability to maintain profit.

Organizations are accustomed to conducting business as usual, which can result in the inexistence (or the lack thereof) of capacity building when it comes to staff skill set acquisition; thus, widening the performance-outcome gap [21]. In Nigeria, it is common practice for nongovernmental organizations to deliver HIV services in hospitals and clinics. Therefore, NGOs must interact with these private institutions in their efforts to tackle the epidemic. However, these entities face issues with conducting in-service training of health care workers at the pri- 
mary health care level since there is no widely utilized framework for providing training to HIV/AIDS personnel in clinics and hospitals who lack the necessary skill set.

The level of ineptitude when it comes to performance outcomes is exacerbated by the existence of an ineffective operational plan regarding human capital. This is made evident by mismatching personnel with constituents that might require certain skills that they do not have. It is often the case that State Commissioners often redirect health personnel to be moved from one facility to another that might be lacking the services/specialties that they were trained in [25]. Moreover, there is also the propensity to allocate high-performing service workers to projects that are likely to succeed. This is primarily due to patient uptake being low or drastically plummeting. However, these workers, in comparison with their low-performing peers are not sent to undesirable areas where the quality of life is bad [26]. Hence, it is usually the case that effective service delivery workers find themselves in urban to suburban areas. This raises concern regarding the distribution of human personnel since it creates an imbalance. This imbalance creates a gap in service provision by which there is a high-concentration of welltrained staff in facilities that offer the best services such as prevention of mother-to-child transmission [PMTCT] and the latest antiretroviral drugs [25]. As a result, there is a density-based clustering of skills across organizations and many staff within nongovernmental organizations are reluctant to provide capacity building opportunities to workers who can easily rise up the ranks and request a transfer to other facilities.

\section{Rational Decision Making}

Providing services to people living with HIV/AIDS involves making crucial decisions, some of which are based on gut feelings and others on rationality. Rational choice theory can be used to understand the manner in which public health services are delivered. Under rational choice theory, individuals make decisions based on rational calculations. These robust decisions involve rigorous in-depth thinking in order to predict all potential possible future-related outcomes. There are two types of rational choice theory to consider: bounded rationality and the rational model. Under bounded rationality, decision makers do not have access to all the information that they need to make critical decisions. Moreover, there is limited time, analytical, and computational abilities needed to evaluate decisions. As a result of all these limitations, managers are more likely to "satisfice" by choosing the first alternative that meets or "satisfies" minimum criteria for solving the problem rather than continuing the search for the optimal solution [26]. More often than not the, choice of the first alternative is often made without examining other critical evidence.

The rational model is similar to an evidence-based management approach since it follows a similar approach in enabling decision makers to make better informed choices. Decisions are made using "facts and information, analysis, and a stepby-step procedure" [27]. Stakeholders become more consistent in their value- 
making choices and methodological in their approach by: defining the problem, identifying decision criteria, allocating weights to the criteria, developing/weighing alternatives, and selecting the best alternative. Evidence-based management can be drawn out from "rational interpretation" and it enables organizations to rely less on subjective opinions and be more objective in their daily practices [27] [28]. According to Baba and Hakemzadeh [29], an EBMgt framework not only makes decisions more rational, but also gives stakeholders a competitive advantage. This is mainly because management by intuition, the alternative approach to basing decisions on evidence [30], is hardly defensible. When managers are not rational, the decisions that they make rely largely on personal experiences or traditional beliefs or weak evidence [31]. However, managers with reliable information and enough time and resources to make and analyze decisions, act on the basis of logic and evidence, rather than on guesswork and hope [32]. As a result, EBMgt can be used to increase the rationality of decisions being made in organizations [33].

\section{Why an Evidence-Based Management Approach?}

Evidence-based management is a unique style of management that stresses the need for decisions to be made based on a combination of critical thinking and the best available evidence. The best available evidence is one that comes from multiple sources if possible-practitioners, scientific literature, organizations, and stakeholders. Six different methods are used to collect evidence from multiple sources. They include: asking, acquiring, appraising, aggregating, applying, and assessing. This is done in a thorough manner because sometimes even the best possible evidence can be misleading. In order to reduce the frequency at which evidence is overstated, there is also a critical appraisal of when and how the evidence is gathered. This establishes trustworthiness and relevance of the data which can be used to either corroborate or refute a test/hypothesis. The use of an evidence-based management approach as it relates to service delivery enables assumptions and current practices to be tested against group conformity that might exist within and across organizations.

An assumption "is a claim, assertion or hypothesis that we believe to be true, even though there is no evidence available (yet)" ([34], p. 21). There is a dire need to confirm or refute assumptions when it comes to understanding issues associated with the delivery of HIV/AIDS services. Moreover, assumptions might be stated and hidden and could have dire effects for teams and beneficiaries of treatment and care. The evidence-based management framework lends itself to defining a new or existing problem in a clear manner while seeking evidence for the preferred solution. A critical appraisal of available evidence would seek to unveil assumptions regarding claims being made especially when the data or current practices are called into question. One of the ways it does so is through the development of the PICOC (patient, intervention, comparison, outcome, and context) model when it comes to clinical and context-specific interventions for mar- 
ginalized populations. For example, could increasing staff training on prevention-of-mother-to-child transmission (PMTCT) reduce the HIV prevalence rate of mothers and children in Northern Nigeria? If so, what according to the evidence would be the best way to approach such efforts, and is there a comparative population to help guide such an intervention? Before this assessment can be made, an underlying assumption that needs to be promulgated is the level of equity that exists when it comes to the resources that facilitate PMTCT training in Northern Nigeria compared to the major metropolitan areas like Lagos or Abuja.

The inability to plan public health interventions carefully with critical evidence wastes resources and leads to suboptimal outcomes with critical evidence. It also perpetuates the cycle of groupthink where there is lack of diversity of thought and conformity in the decision-making process. The grounded nature of evidence-based management also enables groupthink to be challenged since a rigid organizational hierarchy might stifle innovation and a plurality of perspectives. When there is groupthink, there is a higher tendency for decisions to be unanimous even if they require multiple lenses and varying perspectives. The inability to use multiple lenses results in ideas not being properly vetted. Utilizing an evidence-based management perspective when it comes to the conscientious, explicit, and judicious use of evidence diminishes the constant use of heuristics-nonfactual mental notes/shortcuts to problem solving in the workplace.

Heuristics such as:

1) Authority heuristic (belief in the opinion of a person of authority on a subject just because the individual is an authority figure),

2) Representativeness heuristic (mental shortcut that helps us make a decision by comparing information to our mental prototypes),

3) Availability heuristic (mental shortcut that helps us make a decision based on how easy it is to bring something to mind),

4) Halo effect (cognitive bias in which our impression of a person or thing influences how we feel and think about his or her character).

Similar to heuristics, groupthink juxtaposed to organizational politics is killing the Nigerian health industry [35]. Adeniji notes that there are high levels of distrust amongst health professionals and there is a constant attempt to downplay the value of other groups or characterize them as being unimportant within the organization. These microaggressions and toxic work practices often stem from individual experiences with people taking sides and deliberately working to sabotage others. For organizations that have direct care professionals, there is a concerted effort to challenge the headship of the medical doctors. Mitigating the effects of groupthink (especially during conflict) is important because the inability to do so can cause a failure in one's ability to maintain standard practices. Adeniji [35] notes that patients are the ones who suffer when members of organizations make decisions that are "supportive of suggestions made within a group and are dismissive of suggestions made outside the group." Thus, eliminating any rich perspective that can arise from a diversity of thought. According 
to Adeniji, one of the causal factors as to why groupthink is pervasive in Nigerian health organizations can be attributed to the lack of clearly defined responsibilities and weak interpersonal communication between staff.

A best practice when it comes to deconstructing groupthink is by making an effort to promote diverse thinking so as to falsify preconceived notions, views, and judgments that are not based on facts. An environment that fosters improved interpersonal communication is also important when it comes to responding to constructive feedback in order to better serve PLWHA. Furthermore, it would also allow stakeholders in the organization to form decisions without being apprehensive of what the repercussions may be from having a different perspective compared to the rest of the group.

The science of evidence-based management suggests that decision-making happens either in System 1 (fast and intuitive) or System 2 (slow, deliberate, and rational) thinking. In either framework, systematic errors may lead to negative outcomes and unintended consequences. These errors or externalities can result from staff/personnel working in silos or not having a sense of risk susceptibility when it comes to their actions. Social psychologist, Irving L. Janis posits the fact that groupthink arises when there are "illusions of invulnerability" and "unquestioned beliefs" [36]. In System 1 settings, staff members may be quick to jump to conclusions on key programmatic decisions simply because of the perceptions that they have-which might be a byproduct of information asymmetry. Hence, the representativeness heuristic is at play because the predicament being faced might "be too cognitively challenging" or the "preconditions for a solution might not be preapproved" which can lead to a presumed guess. Similarly, entry-level to mid-level staff might be a part of teams whereby there is a high degree of information asymmetry.

Information asymmetry should not only be defined as the lack of awareness as to what is going on within and between teams, but can be classified as the inability for organizations to cross-reference information due to their lack of organizational technology (leadership and processes). Rehfuess et al. [37] note that an evidence-based management (EBMgt) approach to addressing HIV/AIDS services has been noted as being a best practice to addressing public health concerns. EBMgt integrates the best available knowledge from experts and key stakeholders in a manner that benefits the needs of a population. Janati, Hasanpoor, Hajebrahimi, Sadeghi, \& Khezri [38] also suggest that the application of evidence-based management in healthcare enables judgments to be made based on facts and information by analyzing facts appropriately to make these judgments to a greater degree ([38], p. 1).

In coming up with preferred solutions, evidence from practitioners is juxtaposed with that from the organization, scientific literature, and stakeholders. Brownson, Fielding, and Mayhlan [39] point out that evidence-based public health as a tool for effective decision-making is based on four major components: best available research evidence, environment, and organizational context, population characteristics, needs, values and preferences, and resources including prac- 
titioner expertise. In a survey of health professionals, Vogel et al. [40] note that health system decision-making requires a careful consideration of the multitude of variables. As a result, there is a need to support decisions with the best available evidence [40]. Smith and Stewart [41] also argue that evidence tools can also be used as "research-informed advocacy" tools to strengthen policy decisions because they "appear to be objective and credible" [41]. Rousseau [31] refers to the teaching of sociologist Paul Hirschman in asserting that successful evidencebased management understands bureaucratic functions so as to gauge the receptiveness and implications of the recommendations being proposed.

In Cartel of Good Intentions. The Problem of Bureaucracy in Foreign Aid, William Easterly makes note of the fact that "bureaucracy works best where there is high feedback, easily observable outcomes, a high probability that the bureaucratic effort will translate into favorable outcomes, and competitive nature from bureaucracies and other agencies" ([42], p. 4). In looking for evidence for preferred solutions, evidence from practitioners is juxtaposed with that from the organization, scientific literature, and stakeholders. In situations wherein bureaucracies might not be the most effective, evidence-based management can be used to acquire, appraise and aggregate data that might support alternative solutions or show organizational ineptitude. For example, 50\% of HIV/AIDS testing facilities in a particular state might lack treatment counselors during hospital/government strikes. An EBMgt approach might reveal that health workers want consistent paychecks in order to be reluctant to go on strikes. Whereas the evidence from stakeholders might show that the consequences of a strike can be mitigated if people are referred to seek from secondary or tertiary facilities. Thus, there might inadvertently be a transference of service due to the effect of a variable that affects the relation between a predictor and an outcome. In this case, the strike (moderating variable) may cause an overcrowding of these health clinics (predictor) which lessens the quality of providing care (outcome). EBMgt uses the scientific literature in determining what to do when it comes to dealing with hospital flows in resource scarce settings. Moreover, an EBMgt framework would utilize evidence from facilities showing bottlenecks (demand > supply) and how times spent on counseling and scarcity for antiretroviral drugs point at ineffectiveness in the bureaucratic framework.

\section{Promoting Evidence-Based Health Care in Africa}

In a World Health Organization (WHO) interview with Charles SheyWiysonge, Director of the Cochrane Institute South Africa, the use of evidence-based healthcare is framed as a tool for driving research internally based on national priorities [43]. EBMgt in the African context discourages a heavy reliance on research that emerges from high-income countries since such findings may not be applicable to the African context or fail to understand the historical underpinnings of healthcare delivery. The use of an evidence-based approach to address health challenges in Africa facilitates the process of building effective partnerships and collaborating with decision makers. In some cases, it might even lead to the de- 
velopment of new and customized guidelines (based on international frameworks) that are applicable to the local context.

Forland, Rohwer, Klatser, Boer, and Kizza [44] explore a Collaboration for Evidence-Based Healthcare in Africa (CEBHA+) that was established with partners from the following countries: Ethiopia, Uganda, Rwanda, Burundi, Tanzania, Malawi, Zimbabwe, and South Africa ([44], para 1). It was established as a means of achieving the Millennium Development Goals 4, 5 and 6 (reducing child death rates, improving maternal health, and combating HIV/AIDS). The evidence-based collaborators noted that evidence-based approaches to healthcare in Africa are critical to ensuring that Africa-specific research and systematic reviews do not "overgeneralize when making conclusions" ([44], para. 2). Nonetheless, the effective use of evidence-based management approaches in Africa requires sustainable collaborations between researchers, policy-makers, and clinicians. These partnerships should also prioritize the development of strategies for the dissemination and implementation of evidence at all levels. Thus, a significant amount of attention ought to be placed not on the process by which the evidence is gathered, but on how it is disseminated. Rehfuess et al. [37] highlight that $\mathrm{CEBHA}+$ spends significant time in ensuring that research can be conducted with existing interest, expertise, and resources, which in turn leads to the development of customized avenues for reporting findings.

Young, Garner, Clarke, and Volmnik [45] suggest that "evidence-based clinical care, the integration of current best available research evidence with clinical expertise and patient values and preferences, is gaining momentum in the African region" due to the manner in which it is made to fit the local context ([45], p. 2). They cite the Cochrane Review Groups of HIV/AIDS and Infectious Diseases and their audacity to challenge global policy while still ensuring that clinical guideline development was being authored by Africans. The use of evidencebased practices has also led to a shift in the discourse by which government stakeholders are held accountable. As a result, evidence does not confirm policy decisions, but rather informs the direction of the policy. In Nigeria, the Effective Health Care Research Consortium uses an evidence-based approach to inform new or amended policies or guidelines by developing tools for policymakers and improving access to systematic reviews. Similarly, evidence-based approaches to healthcare can become the new norm for nonprofit organizations where answers to relevant research questions are not solely driven by the agendas of funders or researchers [45]. Instead, the methodology behind the data can be used as a means of informing the outcome.

Evidence-based management can be used as a program design tool for shaping the manner in which services are rendered. Howard et al. [46] examine the role of evidence-based science in fostering desirable implementation outcomes for vulnerable women in South Africa [46]. This specific population consumed alcohol and other drugs which contributed to the rate at which they transmitted HIV due to decreasing condom use and increasing risky sex behaviors [46]. They highlight the implementation of the Women's Health Co-Op (WHC) - an evi- 
dence-based women-focused intervention aimed at providing risk-reduction information for alcohol and drugs, HIV and sexually transmitted infections, and gender-based violence. The program facilitates the achievement of these outcomes by providing behavioral skills training for sexual protection and safer sex communication [46]. Through focus group discussions and interviews, it became apparent that the sensitivity of topics made it arduous for interventions to be adopted. Other issues that existed were: length of the intervention, delivery format, and staffing constraints. The researchers found that an evidence-based approach is not a be-all and end-all tool for "addressing issues of substance use, sexual risk, and intimate partner violence" ([46], para. 3). The design of evidence-based health care approaches requires a close examination of staffing constraints; specifically, the need for staff to have the "necessary training to conduct behavioral interventions and to properly communicate with patients" ([46], para. 30). Effective delivery of intervention programs requires that knowledge gaps in delivering collaborative and integrated services are closed so as to mitigate any work that happens in silos.

Closing knowledge gaps enables stakeholders to derive pathways for customizing interventions. Howard et al. [46] highlight the fact that through the use of evidence-based approaches, three positive facilitators are evident: 1) high perceived need for the intervention in the community-health providers found innovative ways to invest resources despite the constraints they faced. 2) the participants were willing to participate in the program because of the perceived benefits, iii. Outside of monetary gains, the staff were also committed and more invested in the program. Implementing the WHC program enabled staff to get additional training, mentoring, and capacity building. The use of evidence-based approaches/interventions requires adaptability and keen knowledge of the context or on-the-ground conditions. Even after the project was conducted, a community collaborative board (CCB) was formed that informed other stakeholders. In order to achieve optimal outcomes and make the HIV program even more sustainable, the CCB recommended the use of community workers rather than nurses to deliver interventions. Moreover, they also modified the intervention content to "address concerns about intervention length and sensitivity issues raised during the formative phase" so as to increase the effectiveness of services ([46], para. 48).

Rehfuess et al. [37] postulate that evidence-based approaches increase value and reduce waste [47] [48] [49] especially in resource-constrained settings. They also suggest that it is a best practice for addressing health problems. In the African context, they present the case that evidence-based decision-making ought to happen through a consortium of health-care practitioners and policy-makers. This would allow for a thorough assessment of "cost-effectiveness", "persona; values", "preferences", "feasibility", "acceptability", and "equity".

Ledger [50] argues that "taking an evidence-based approach to management is not of itself a comprehensive solution to the problems facing organizations today" ([50], para. 18). The reason for this is that decision-making in an EBMgt 
framework is more transparent and traceable which can be antithetical to organizational practices. Nonetheless, appraising different forms of evidence is not an easy feat since clinical and non-clinical knowledge can vary in their level of importance. In order to mitigate this variance, it is important that attention is paid to "efforts to marginalize valuable professional experience in pursuit of an idealized form of scientific management and organizational design" ([50], p. 96).

Placing emphasis on professional skill set is critical to ensure that service effectiveness is a top priority across all levels of the value chain. Janati et al. [38] call attention to four basic kinds of evidence that managers can use in their daily practices. They include:

1) Hard evidence: Scientific and research evidence, facts and information, political-social development plans, manager's professional expertise and ethicalmoral evidence.

2) Predictors: Stakeholder values and expectations, functional behavior, knowledge, key competencies and skill, evidence sources, evidence levels, uses and benefits of government programs.

3) Evidence-based management barriers: Managers' personal characteristics, decision-making environment, training and research systems, organizational issues.

4) Evidence-based management processes: Asking, acquiring, appraising, aggregating, applying.

When applied effectively, these different enabling factors can significantly strengthen a manager's decision-making ability and lead to better organizational outcomes. Furthermore, the authors advocate for the use of this framework across different levels in a nonprofit organization. This is because EBMgt can significantly reduce the impact that red tape has on critical decisions while still standardizing processes in an accountable and transparent manner. Furthermore, it can give rise to a system of checks and balances which can be crucial in mitigating corruption within an organization and the effects of other unforeseen challenges.

\section{The Critical Role of NGOs in Combating HIV/AIDS}

Leonard and Leonard [51] explore the role of NGOs in an unpredictable African healthcare landscape by presenting a compelling argument that NGOs have the "institutional capacity to deliver high quality care whereas private practitioners, even with good intentions will not succeed" ([51], para. 2). They assert that NGOs are less susceptible to information asymmetry-as compared to their government counterparts. This can be attributed to the fact that NGOs are not limited by preimposed structures and they primarily operate in a marketplace where everything is fair game. Therefore, NGOs are better positioned to use effective information flows in an EBMgt framework to improve organizational outcomes.

Less information asymmetry can make institutions highly-functional. Leonard 
and Leonard [51] also highlight that the public perception of NGOs in most African countries is far better off than government services to the point that "most people are prepared to pay a premium over government facility charges in order to use them" ([51], p. 20). They also make the case that a patient is likely to use an NGO service since that patient's focus is on maximizing the quality of his/her medical care, and has a stronger vote of confidence in the service provided by NGOs. Thus, he/she decides to go with an NGO for care/treatment because of a stronger belief that utilizing the services of the organization is likely to lead to better outcomes. The tendency for NGOs to achieve better outcomes has started the phenomenon of various national governments contracting out health services to NGOs. In countries like Zimbabwe, Tanzania, and Ghana, mission health services are now running district hospitals. Although the outcomes of NGOs managing hospitals have not all been positive, there is greater flexibility to hire and fire staff based on budget, resources, and quality outcome measures.

\section{Conclusion}

Evidence-based management is a rigorous framework that can be used for understanding how a multitude of factors can position an organization to achieve its theory of change, which in turn can lead to sustainable impact in the long run. Incorporating the use of evidence in everyday organizational behavior involves not only looking at the manner in which data is aggregated, but also how it is disseminated. As a mechanism for informing decision-making, EBMgt can reduce information gaps amongst stakeholders. It can also foster a greater quality of service by looking at how organizations fair comparatively amongst each other. In order to ensure that the evidence is not manipulated, nonprofit organizations are often viewed as being best suited for collecting evidence since they are not heavily plagued by systemic corruption and political tides, compared to their government counterparts. Nonetheless, it is important that future research looks into how NGOs that share a common vision and a set of values are able to work together to meet the interest of citizens, even if they are competing for the same funding pools. Organizations that do this are not only able to reduce the service gap for key populations, but are also able to improve their learning capacities, reduce the information gap in their networks, and create a more resilient environment for their employees and stakeholders.

\section{Conflicts of Interest}

The author declares no conflicts of interest regarding the publication of this paper.

\section{References}

[1] Grillo, G. and UNAIDS (2020) 38 Million People Are Living with HIV around the World.

https://www.unaids.org/en/resources/infographics/people-living-with-hiv-around-t he-world 
[2] NACA (2017) National Strategic Framework on HIV and AIDS: 2017-2021. https://www.childrenandaids.org/sites/default/files/2017-11/NATIONAL-HIV-AN D-AIDS-STRATEGIC-FRAMEWORK.pdf

[3] UNAIDS (2017) Data Book.

[4] Ankomah, A., Omoregie, G., Akinyemi, Z., Anyanti, J., Ladipo, O. and Adebayo, S. (2011) HIV-Related Risk Perception among Female Sex Workers in Nigeria. HIVI AIDS (Auckland, N.Z.), 3, 93-100. https://doi.org/10.2147/HIV.S23081

[5] Iriaye, D.A., Suleiman, I., Obianwu, O., Adebajo, S., Eluwa, G., Njab, J., Ahonsi, B., et al. (2014) Patterns of Drug Use among People Who Inject Drugs (PWID) and Their Implications for Sexually Transmitted Infections in Northern Nigeria. AIDS Research and Human Retroviruses, 30, A277-A278.

https://doi.org/10.1089/aid.2014.5626.abstract

[6] NOI-Polls (2016) Gay Rights: Perceptions of Nigerians on LGB Rights Poll Report.

[7] Balogun, A. (2010) HIV/AIDS Epidemic in the History of Nigeria, 1986-2007. Journal of the Historical Society of Nigeria, 19, 166-176.

http://www.jstor.org/stable/41857169

[8] Anochie, I. and Ikpeme, E. (2003) AIDS Awareness and Knowledge among Primary School Children in Port Harcourt Metropolis. Nigerian Journal of Medicine: Journal of the National Association of Resident Doctors of Nigeria, 12, 27-31.

[9] Dalhatu, I., Onotu, D., Odafe, S., Abiri, O., Debem, H., Agolory, S., Ellerbrock, T.V., et al. (2016) Outcomes of Nigeria's HIV/AIDS Treatment Program for Patients Initiated on Antiretroviral Treatment between 2004-2012. PLOS ONE, 11, e0170912. https://doi.org/10.1371/journal.pone.0165528

[10] Ogbuji, C.Q. (2005) Knowledge about HIV/AIDS and Sexual Practice among University of Ibadan Students. African Journal of Medicine and Medical Sciences, 34, 25-31.

[11] Entonu, P. and Agwale, S. (2007) A Review of the Epidemiology, Prevention and Treatment of Human Immunodeficiency Virus Infection in Nigeria. Brazilian Journal of Infectious Diseases, 11, 82-99.

https://doi.org/10.1590/S1413-86702007000600011

[12] Deshi, O.A. (1987) Knowledge, Attitude and Practice of AngwanRogo Residents to AIDS. M.E.D. Thesis, University of Jos, Jos.

[13] Ohnishi, M., Nakamura, K., Kizuki, M., Seino, K., Inose, T. and Takano, T. (2008) Caregivers' and Non-Caregivers' Knowledge Regarding HIV/AIDS and Attitude towards HIV/AIDS and Orphans in Nigeria. Health \& Social Care in the Community, 16, 483-492. https://doi.org/10.1111/j.1365-2524.2007.00757.x

[14] Oral Interview with Mr. Victor Udoidiong, Information Officer, NACA Headquarters, Abuja (04/11/2008).

[15] Itiola, A.J. and Agu, K.A. (2018) Country Ownership and Sustainability of Nigeria's HIV/AIDS Supply Chain System: Qualitative Perceptions of Progress, Challenges and Prospects. Journal of Pharmaceutical Policy and Practice, 11, Article No. 21.

https://joppp.biomedcentral.com/articles/10.1186/s40545-018-0148-8 https://doi.org/10.1186/s40545-018-0148-8

[16] Oleribe, O.O., Oladipo, O., Osita-Oleribe, P., Nwachukwu, C., Nkwopara, F., Ekom, E., Nwabuzor, S., Iyalla, G., Onyewuchi, K., Olutola, A., Nwanyanwu, O. and Nsubuga, P. (2014) Commonization of HIV/AIDS Services in Nigeria: The Need, the Processes and the Prospects. The Pan African Medical Journal, 19, 329.

https://doi.org/10.11604/pamj.2014.19.329.5138 
[17] Akor, O. (2019) NEPHWAN Tasks FG on Support for People Living with HIV/AIDS. Daily Trust.

https://www.dailytrust.com.ng/nepwhan-tasks-fg-on-sup=port-for-people-living-wi th-hiv-aids

[18] Tyler, L. and Dickinson, C. (2006) The Link between Corruption and HIV/Aids. IAPAC Monthly, 12, 37-39. https://pubmed.ncbi.nlm.nih.gov/17249134

[19] Smith, D.J. (2010) Corruption, NGOs, and Development in Nigeria. Third World Quarterly, 31, 243-258. http://www.jstor.org/stable/25677769 https://doi.org/10.1080/01436591003711975

[20] Transparency International (n.d.) Corruption Index. Transparency.org. https://www.transparency.org/en/\#

[21] Smith, D.J. (2012) Aids NGOS and Corruption in Nigeria. Health \& Place, 18, 475480. https://www.ncbi.nlm.nih.gov/pmc/articles/PMC3319657 https://doi.org/10.1016/j.healthplace.2011.11.002

[22] Nnochiri, I. (2011) HIV/AIDS SCAM: How 7 NGOs Took Nigeria for a Ride, by ICPC. Vanguard News.

https://www.vanguardngr.com/2011/07/hivaids-aids-scamhow-7-ngos-took-nigeria -for-a-ride-by-icpc

[23] Avert (2018) HIV and AIDS in Nigeria. https://www.avert.org/professionals/hiv-around-world/sub-saharan-africa/nigeria

[24] Smith, D.J. (2011) Benefiting from AIDS in Contemporary Nigeria. Anthropology Now, 3, 1-9. https://www.ncbi.nlm.nih.gov/pmc/articles/PMC4222075 https://doi.org/10.1080/19492901.2011.11728329

[25] Abimbola, S., Olanipekun, T., Schaaf, M., Negin, J., Jan, S. and Martiniuk, A. (2016) Where There Is No Policy: Governing the Posting and Transfer of Primary Health Care Workers in Nigeria. The International Journal of Health Planning and Management, 32, 492-508. https://www.ncbi.nlm.nih.gov/pmc/articles/PMC5716250 https://doi.org/10.1002/hpm.2356

[26] McDonough, A. and Rodriguez, D.C. (2010) How Donors Support Civil Society as Government Accountability Advocates: A Review of Strategies and Implications for Transition of Donor Funding in Global Health. Globalization and Health, 16, Article No. 110. https://doi.org/10.1186/s12992-020-00628-6

[27] Uzonwanne, F.C. (2016) Rational Model of Decision Making. In: Farazmand, A., Ed., Global Encyclopedia of Public Administration, Public Policy, and Governance, Springer, Cham. https://doi.org/10.1007/978-3-319-31816-5 2474-1

[28] Boundless (n.d.) Evidence-Based Decision Making.

[29] Baba, V.V. and Hakemzadeh, F. (2012) Toward a Theory of Evidence Based Decision Making. Management Decision, 50, 832-867. https://doi.org/10.1108/00251741211227546

[30] Gaynard, J. (2010) Creativity, Innovation, KM and French Management. http://johngaynardcreativity.blogspot.com/2010/01/intuitive-management-vs-evide nce-based.html

[31] Rousseau, D.M. (2006) Is There Such a Thing as "Evidence-Based Management"? Academy of Management Review, 31, 256-269. https://doi.org/10.5465/amr.2006.20208679

[32] Pfeffer, J. and Sutton, R.I. (2006) Hard Facts, Dangerous Half-Truths, and Total Nonsense: Profiting from Evidence-Based Management. Harvard Business School Press, Boston, 6 . 
[33] Martelli, P.F. and Hayirli, T.C. (2018) Three Perspectives on Evidence-Based Management: Rank, Fit, Variety. Management Decision, 56, 2085-2100. https://doi.org/10.1108/MD-09-2017-0920

[34] Barends, E. and Rousseau, D.M. (2018) Evidence-Based Management-How to Use Evidence to Make Better Organizational Decisions. Kogan Page, London.

[35] Adeniji, F.O. (2010) Group-Think among Health Workers; the Nigerian Perspective. Researcher, 2, 1-4. http://www.sciencepub.net/researcher/research0205/01 0880 research0205 1 4.pdf

[36] Hart, P.T. (1991) Irving L. Janis' Victims of Groupthink. Political Psychology, 12, 247-278. https://doi.org/10.2307/3791464

[37] Rehfuess, E.A., Durão, S., Kyamanywa, P., Meerpohl, J.J., Young, T. and Rohwer, A. (2015) An Approach for Setting Evidence-Based and Stakeholder-Informed Research Priorities in Low- and Middle-Income Countries. Bulletin of the World Health Organization, 94, 297-305. https://doi.org/10.2471/BLT.15.162966

[38] Janati, A., Hasanpoor, E., Hajebrahimi, S., Sadeghi-Bazargani, H. and Khezri, A. (2018) An Evidence-Based Framework for Evidence-Based Management in Healthcare Organizations: A Delphi Study. Ethiopian Journal of Health Sciences, 28, 305-314. https://doi.org/10.4314/ejhs.v28i3.8

[39] Brownson, R.C., Chriqui, J.F. and Stamatakis, K.A. (2009) Understanding EvidenceBased Public Health Policy. American Journal of Public Health, 99, 1576-1583. https://doi.org/10.2105/AJPH.2008.156224

[40] Vogel, D.L., Bitman, R.L., Hammer, J.H. and Wade, N.G. (2013) Is Stigma Internalized? The Longitudinal Impact of Public Stigma on Self-Stigma. Journal of Counseling Psychology, 60, 311-316. https://doi.org/10.1037/a0031889

[41] Smith, K. and Stewart, E. (2017) Academic Advocacy in Public Health: Disciplinary "Duty" or Political "Propaganda"? Social Science \& Medicine, 189, 35-43. https://doi.org/10.1016/j.socscimed.2017.07.014

[42] Easterly, W. (2002) The Cartel of Good Intentions: Bureaucracy versus Markets in Foreign Aid. Center for Global Development, Washington DC.

https://doi.org/10.2139/ssrn.999981

[43] Wiysonge, C.S. (2017) Promoting Evidence-Based Health Care in Africa. Bulletin of the World Health Organization, 95, 616-617. https://doi.org/10.2471/BLT.17.030917

[44] Forland, F., Rohwer, A.C., Klatser, P., Boer, K. and Mayanja-Kizza, H. (2013) Strengthening Evidence-Based Healthcare in Africa. Evidence Based Medicine, 18, 204-206. https://doi.org/10.1136/eb-2012-101143

[45] Young, T., Garner, P., Clarke, M. and Volmink, J. (2017) Series: Clinical Epidemiology in South Africa. Paper 1: Evidence-Based Health Care and Policy in Africa: Past, Present, and Future. Journal of Clinical Epidemiology, 83, 24-30. https://doi.org/10.1016/j.jclinepi.2016.06.006

[46] Howard, B.N., Van Dorn, R., Myers, B.J., Zule, W.A., Browne, F.A., Carney, T. and Wechsberg, W.M. (2017) Barriers and Facilitators to Implementing an EvidenceBased Woman-Focused Intervention in South African Health Services. BMC Health Services Research, 17, 746. https://doi.org/10.1186/s12913-017-2669-2

[47] Chalmers, I., Bracken, M.B., Djulbegovic, B., Garattini, S., Grant, J., Gülmezoglu, A.M., Oliver, S., et al. (2014) How to Increase Value and Reduce Waste When Research Priorities Are Set. The Lancet, 383, 156-165.

https://doi.org/10.1016/S0140-6736(13)62229-1

[48] Ioannidis, J.P., Greenland, S., Hlatky, M.A., Khoury, M.J., Macleod, M.R., Moher, 
D. and Tibshirani, R. (2014) Increasing Value and Reducing Waste in Research Design, Conduct, and Analysis. The Lancet, 383, 166-175.

https://doi.org/10.1016/S0140-6736(13)62227-8

[49] Macleod, M.R., Michie, S., Roberts, I., Dirnagl, U., Chalmers, I., Ioannidis, J.P., Glasziou, P., et al. (2014) Biomedical Research: Increasing Value, Reducing Waste. The Lancet, 383, 101-104. https://doi.org/10.1016/S0140-6736(13)62329-6

[50] Ledger, J. (2010) The Gold Standard of Management? Evidence-Based Management and Healthcare Delivery. London Journal of Primary Care, 3, 93-97. https://doi.org/10.1080/17571472.2010.11493310

[51] Leonard, K.L. and Leonard, D.K. (1999) Asymmetric Information and the Role of NGOs in African Health Care. SSRN Electronic Journal.

https://doi.org/10.2139/ssrn.176908 